
$\mathrm{SCIDOC}$

\section{International Journal of Dentistry and Oral Science (IJDOS) ISSN: 2377-8075}

\title{
A Comparative Evaluation of 2 Point VS 3-Point Fixation of Zygomatic Bone Fractures in Adult Patients
}

Research Article

Srikar MV $\mathrm{MV}^{1}$, Vidya $\mathrm{KC}^{2 *}$, Pathapati Srinivas Raju ${ }^{3}$, Jugajyoti Pathi ${ }^{4}$

${ }^{1}$ Professor, and HOD, Department of Oral and Maxillofacial Surgery, Kalinga Institute of Dental Sciences, KIIT Deemed to be University, Patia Campus 5, Bhubaneswar, Odisha, India.

${ }^{2}$ Reader, Department of Oral and Maxillofacial Surgery, Kalinga Institute of Dental sciences, KIIT Deemed to be University, Patia Campus 5, Bhubaneswar, Odisha, India.

${ }^{3}$ Reader, Department Oral and Maxillofacial Surgery, GSL Dental College, Rajahmundry, Andra Pradesh, India.

${ }^{4}$ Senior Lecturer, Department of Oral and Maxillofacial Surgery, Kalinga Institute of Dental sciences, KIIT Deemed to be University, Patia Campus 5 , Bhubaneswar, Odisha, India.

\section{Abstract}

Background: The prominant zygomatic portion is predisposing factor for the facial injuries. Open reduction \& internal fixation of simple displaced fractures of the zygoma in an effort to define the simplest method of achieving post reduction stability. Aim: The present study was conducted to compare 2 point and 3-point internal fixation technique for the management of zygomatic bone fractures.

Materials \& Methods: 56 patients of zygomatic bone fracture were divided into 2 groups. Group I patients were treated with 2-point fixation and group II patients treated with 3-point fixation technique. In all patients, clinical features and outcome of treatment was recorded.

Results: The mean enopthalmos in group I was $2.5 \mathrm{~mm}$ and in group II was $1.22 \mathrm{~mm}$. The mean vertical dystopia in group I was $2.14 \mathrm{~mm}$ and group II was $0.96 \mathrm{~mm}$ respectively. The difference was significant $(\mathrm{P}<0.05)$. Malar asymmetry was grade I seen in 8 in group I and 9 in group II, grade II seen 8 in group I and 9 in group II, grade III seen 12 in group I and 10 in group II. The difference was non- significant $(\mathrm{P}>0.05)$.

Conclusion: Authors found that zygomatic bone fracture can be managed with 2 point as well as 3 point plates. However,threepoint fixation appears better as compared to two point fixation.

Keywords: Zygomatic Bone; Enopthalmos; Malar Ssymmetry.

\section{Introduction}

Following road side accident, face being the prominent part of body tends to receive injures. The prominent zygomatic portion is predisposing factor for the facial injuries. The position of zygomatic bone is such that in $50 \%$ of cases of facial injuries, it is the second most common mid-facial fractured bone [1].

Zygomatic bone is a paired bone which articulates with the temporal bone, the maxilla, the frontal bone, and the sphenoid bone. It forms the prominence of the cheek, part of the lateral wall and floor of the orbit, and parts of the temporal and infratemporal fossa with its situation at the upper and lateral part of the face. It presents four processes; the fronto-sphenoidal, orbital, maxillary, and temporal, four borders and a malar and a temporal surface [2]. It is frequently fractured bone and there is male predominance. The major reason for fracture is road side accident or assault. There is anaverage of male to female ratio of 3-5:1 in developed countries, whereas in underdeveloped countries, the ratio is on average 10-40:1 [3].

The management of zygomatic bone fractures demands careful assessment of fractured site. Numerous surgical techniques have been invented for the reduction of zygomatic complex fracture. Procedures such as Keen's approach, Gillies' approach, bicoronal scalp flap approach or the more popular Dingman's approach. There is always debate whether two point or three-point internal fixation technique is useful for the management of zygomatic

\section{*Corresponding Author:}

Dr. Vidya KC,

Reader, Department of Oral and Maxillofacial Surgery, Kalinga Institute of Dental sciences, KIIT Deemed to be University, Patia Campus 5, Bhubaneswar, Odisha, India. E-mail: drvidya1984@gmail.com

Received: October 20, 2020

Accepted: November 01, 2020

Published: November 07, 2020

Citation: Srikar MV, Vidya KC, Pathapati Srinivas Raju, Jugajyoti Pathi. A Comparative Evaluation of 2 Point VS 3-Point Fixation of Zygomatic Bone Fractures in Adult Patients. Int J Dentistry Oral Sci. 2020;S2:02:005:18-20. doi: http://dx.doi.org/10.19070/2377-8075-SI02-02005

Copyright: Vidya $\mathbf{K C}^{\circ} 2020$. This is an open-access article distributed under the terms of the Creative Commons Attribution License, which permits unrestricted use, distribution and reproduction in any medium, provided the original author and source are credited. 
bone fractures. However, open reduction \& internal fixation of simple displaced fractures of the zygoma in an effort to define the simplest method of achieving post reduction stability [4]. The present study was conducted to compare 2 point and 3 point internal fixation technique in zygomatic bone fractures in adults.

\section{Materials and Methods}

The present study was conducted in department of Oral \& Maxillofacial surgery. It comprised of 56 patients of zygomatic bone fracture. The diagnosis of zygomatic bone fractures was made with careful clinical examination and with extraoral radiographs. Prior to study institutional ethical clearance was obtained. Informed consent was obtained from participating subjects.Patients above 18 years of age and without systemic disease were included while patients below 18 years of age, non- cooperative and patients with fracture more than 72 hours were excluded.

Patient information such as name, age, gender etc. was recorded. They were divided into 2 groups. Group I patients were treated with 2 point fixation and group II patients treated with 3 point fixation technique. In group I patients, 2 point pins were given, first at inferior orbital rim and second at fronto-zygomatic suture. In group II, 3 point fixation, first at inferior orbital rim and second at fronto- zygomatic suture and third at zygomatico-maxillary buttress was given. In all patients, clinical features and outcome of treatment was recorded. All patients were recalled regularly.

Results thus obtained were subjected to statistical analysis using chi square test. $\mathrm{P}$ value $<0.05$ was considered significant.

\section{Results}

Table 1, shows that mean enopthalmos in group I was $2.5 \mathrm{~mm}$ and in group II was $1.22 \mathrm{~mm}$. The mean vertical dystopia in group I was $2.14 \mathrm{~mm}$ and group II was $0.96 \mathrm{~mm}$ respectively. The difference was significant $(\mathrm{P}<0.05)$. Malar asymmetry was grade I seen in 8 in group I and 9 in group II, grade II seen 8 in group I and 9 in group II, grade III seen 12 in group I and 10 in group II. The difference was non- significant $(\mathrm{P}>0.05)$. Table 2 , shows that peri-orbital swelling was seen in 22 in group I and 20 in group II, subconjuctival hemorrhage in 21 in group I and 15 in group II, infra-orbital sensation 17 in group I and 12 in group II, eternal laceration seen 11 in group I and 8 in group II and vision loss 4 in group I and 1 in group II. The difference was significant $(\mathrm{P}<0.05)$.

\section{Discussion}

Zygomatic bone is also known as buttress bone is prone to get fractured. The prominence of zygomatic bone is the major contributing factor leading to fracture [5]. However, the architectural pattern of zygomatic bone allows it to withstand blows of great forces without fracturing. Because of such heavy forces zygomatic bone gets separated from adjacent bone at or near the suture lines [6]. The separation may lead to zygomatico-maxillary complex, zygomatic-complex or orbito-zygomatic fracture. It is difficult to treat these complexe. They are seen as isolated or in association with other facial fractures due to the complex midface anatomy [7]. The present study was conducted to compare 2 point and 3 point internal fixation technique in zygomatic bone fractures in adults.

In present study, in group I, there were 18 males and 10 females and in group II, there were 17 males and 11 females. Bradley et al [8] in their study, patients were treated with one-point fixation. It was found that the zygomatico-maxillary (ZM) buttress was the most popular fixation point seen in $90 \%$ of cases. In $70 \%$ of cases, the commonest choice for two-point fixations was ZM buttress and fronto-zygomatic (FZ) suture. Buccal sulcus incision was used for $\mathrm{ZM}$ access in all cases. For FZ access, in 56\% of cases, upper blepharoplasty incision was the most common site. for Infra Orbital Margin Access Trans Conjuctival Incision Was The Most Common In $75 \%$ Of The Cases. There was no significant association between number of fixation points and presence of associated injuries, impact of injury, or time to operation. There were no post-operative complications.

We found that mean enopthalmos in group I was $2.5 \mathrm{~mm}$ and in group II was $1.22 \mathrm{~mm}$. The mean vertical dystopia in group I

Table 1. Comparison of parameters.

\begin{tabular}{|c|c|c|c|c|}
\hline Parameters & & Group I & Group II & P value \\
\hline Enopthalmos (Mean) & & 2.5 & 1.22 & 0.01 \\
\hline Vertical dystopia (Mean) & & 2.14 & 0.96 & 0.02 \\
\hline \multirow{3}{*}{ Malar asymmetry } & Grade I & 8 & 9 & 0.9 \\
\cline { 2 - 5 } & Grade II & 8 & 9 & 0.9 \\
\cline { 2 - 5 } & Grade III & 12 & 10 & 0.71 \\
\hline
\end{tabular}

Table 2. Other clinical features in patients.

\begin{tabular}{|c|c|c|c|}
\hline Clinical features & Group I & Group II & P value \\
\hline Peri-orbital swelling & 22 & 20 & 0.8 \\
\hline Subconjuctival hemorrhage & 21 & 15 & 0.06 \\
\hline Infra-orbital sensation & 17 & 12 & 0.07 \\
\hline Eternal laceration & 11 & 8 & 0.02 \\
\hline Vision loss & 4 & 1 & 0.01 \\
\hline
\end{tabular}


was $2.14 \mathrm{~mm}$ and group II was $0.96 \mathrm{~mm}$ respectively. Malar asymmetry was grade I seen in 8 in group I and 9 in group II, grade II seen 8 in group I and 9 in group II, grade III seen 12 in group I and 10 in group II.

Ashwin et al[9] found that road traffic accident accounted as the leading cause of fracture in $60.9 \%$ cases followed by self-fall in $28.3 \%$, assault in $6.5 \%$ cases. Open reduction and internal fixation was carried out in $73.9 \%$ cases. 1 -point fixation was seen in $28.3 \%$, 2 -point fixation in 32.6\% cases and 3-point fixation in 13\% cases. We observed that peri-orbital swelling was seen in 22 in group I and 20 in group II, subconjuctival hemorrhage in 21 in group I and 15 in group II, infra-orbital sensation 17 in group I and 12 in group II, eternal laceration seen 11 in group I and 8 in group II and vision loss 4 in group I and 1 in group II.

Kim et al concluded from their study that one-point fixation of the zygomatic buttress using an u-HA / PLLA plate showed and acceptable clinical outcome in patients with ZMC fractures [10].

The goal of present treatment of zygomatic fractures is to restore and maintain pre-injury facial skeletal configuration. A miniplate applied across the fronto-zygomatic suture will resist translator movement and also rotation along an axis perpendicular to the plane of miniplate because of the width of the plate. To improve stabilization, an additional plate is to be applied in a manner where the weak axis of both plates does not coincide with a line connecting them [11].

Assessment of 2-point fixation or 3 point fixation in zygomatic bone fracture may be helpful in ensuring successful treatment planning in pro active of primary care.

The shortcoming of the study is that we did not assess outcome of the treatment for longer period.

\section{Conclusion}

Authors Found That Zygomatic Bone Fractures Can Be Managed With Either Two Or Three Point Fixation ,However Three Point
Fixation Appears Better As Compared To Two Point Fixation In Surgical Treatment Of These Fractures.

\section{References}

[1]. Starch-Jensen T, Linnebjerg LB, Jensen JD. Treatment of zygomatic complex fractures with surgical or nonsurgical intervention: A retrospective study. Open Dent. J. 2018;12:377.

[2]. Syarif AN, Bangun K. Assessing symmetry using the mirror stand device with manual and software-assisted methods in postoperative zygomatic fracture patients. JPhCS. 2017 Aug;884(1):012066.

[3]. Sridhar P, Sandeep S, Prasad K, Lalitha RM, Ranganath K, Munoyath KS Comparative evaluation of single point fixation at zygomatic buttress and fronto zygomatic rim in zygomatic complex fractures-a prospective study. JDOR. 2017;13(2):27-39.

[4]. Dakir A, Muthumani T, Prabu NP, Mohan R, Maity A. One point fixation of zygomatic tripod fractures in the zygomatic buttress through Keen's intraoral approach: A review of 30 cases. J Pharm Bioallied Sci. 2015 Apr;7(Suppl 1):S238-41.Pubmed PMID: 26015722.

[5]. Birgfeld CB, Mundinger GS, Gruss JS. Evidence-Based Medicine: Evaluation and Treatment of Zygoma Fractures. Plast Reconstr Surg. 2017 Jan;139(1):168-180.Pubmed PMID: 28027253.

[6]. Chen CH, Mao SH, Shyu VB, Chen CT. Single buccal sulcus approach with fluoroscan assistance for the management of simple zygomatic fractures. Ann Plast Surg. 2015 May;74 Suppl 2:S80-4. Pubmed PMID: 25695447.

[7]. Dakir A, Muthumani T, Prabu NP, Mohan R, Maity A. One point fixation of zygomatic tripod fractures in the zygomatic buttress through Keen's intraoral approach: A review of 30 cases. J Pharm Bioallied Sci. 2015 Apr;7(Suppl 1):S238-41.Pubmed PMID: 26015722.

[8]. Bradley D, Leung B, Saxena S, Dungarwalla M, Chapireau D, Fan K. Surgical management of zygomatic complex fractures in a major trauma centre. Plast Aesthet Res. 2019 May 24;6-11.

[9]. Ashwin DP, Rajkumar GC. A study on assessing the etiology and different treatment modalities of zygomaticomaxillary complex fracture. Int J Contemp Med Res. 2017;4(6):1423-30.

[10]. Kim SY, Nam SM, Park ES, Kim YB. Evaluation of one-point fixation for zygomaticomaxillary complex fractures using a three-dimensional photogrammetric analysis. J Otolaryngol Head Neck Surg. 2019 Jul 30;48(1):36. Pubmed PMID: 31362786.

[11]. Neovius E, Fransson M, Persson C, Clarliden S, Farnebo F, Lundgren TK. Long-term sensory disturbances after orbitozygomatic fractures. J Plast Reconstr Aesthet Surg. 2017 Jan;70(1):120-126.Pubmed PMID: 27769603. 